\title{
Using the Gartner Hype Cycle to Evaluate the Adoption of Emerging Technology Trends in Higher Education - 2013 to 2016
}

\author{
Tania Prins loo $^{1 *}$, JP van Deventer ${ }^{1}$ \\ ${ }^{1}$ University of Pretoria, Pretoria, South Africa \\ tania.prinsloo@up.ac.za \\ phil.vandeventer@up.ac.za
}

\begin{abstract}
The landscape of higher education is changing, with more technosavvy students entering these institutions. The aim of this paper is to identify the trends of the Gartner Hype Cycles for Emerging Technologies for 2013 and 2016 and to compare the rate of adoption by higher education institutions worldwide. The research approach is a quantitative meta-analy sis. Results indicate that higher education institutions are slow to adopt emerging technologies and rather adopt technologies once they have become common in the every day lives of people. A possible solution is to find innovative and cheaper ways of incorporating the emerging trends in higher education.
\end{abstract}

Keywords. Gartner's Hype Cycle, Emerging Technologies, Higher Education.

\section{Introduction}

Higher education is changing rapidly due to globalization and increasing internationalization [2]. The student entering higher education today is technologically much further advanced than five years ago [4]. Technology is not only embedded in their everyday lives, but also part of their higher education experience [5]. The landscape of higher education is adapting to new technologies and trends, with institutions implementing new technologies to attract students [2]. Technology adoption, however, is different for diverse technologies [1]. The aim of this article is to compare the rate of adoption of emerging technologies by higher education institutions from 2013 to 2016, to the Gartner Hype Cycle for Emerging Technologies, to determine if universities are staying ahead or lagging behind.

\section{Background}

Roy Amara is quoted as saying "we tend to overestimate the effect of a technology in the short run and underestimate the effect in the long run" [3]. Higher education institutions need to position themselves to remain competitive in the technological do- 
main. One way of measuring the performance of these institutions is by comparing them to Gartner's Hype Cycle for Emerging Technologies.

\subsection{The Gartner Hype Cycle}

The Gartner Hype Cycle is a graphical representation of the newest emerging technology trends worldwide and is published annually from 1995 [7]. The hype cycle starts with the overenthusiastic adopters, through five phases, until the new technology finds its use in the market [13]. Figure 1 illustrates the hype curve.

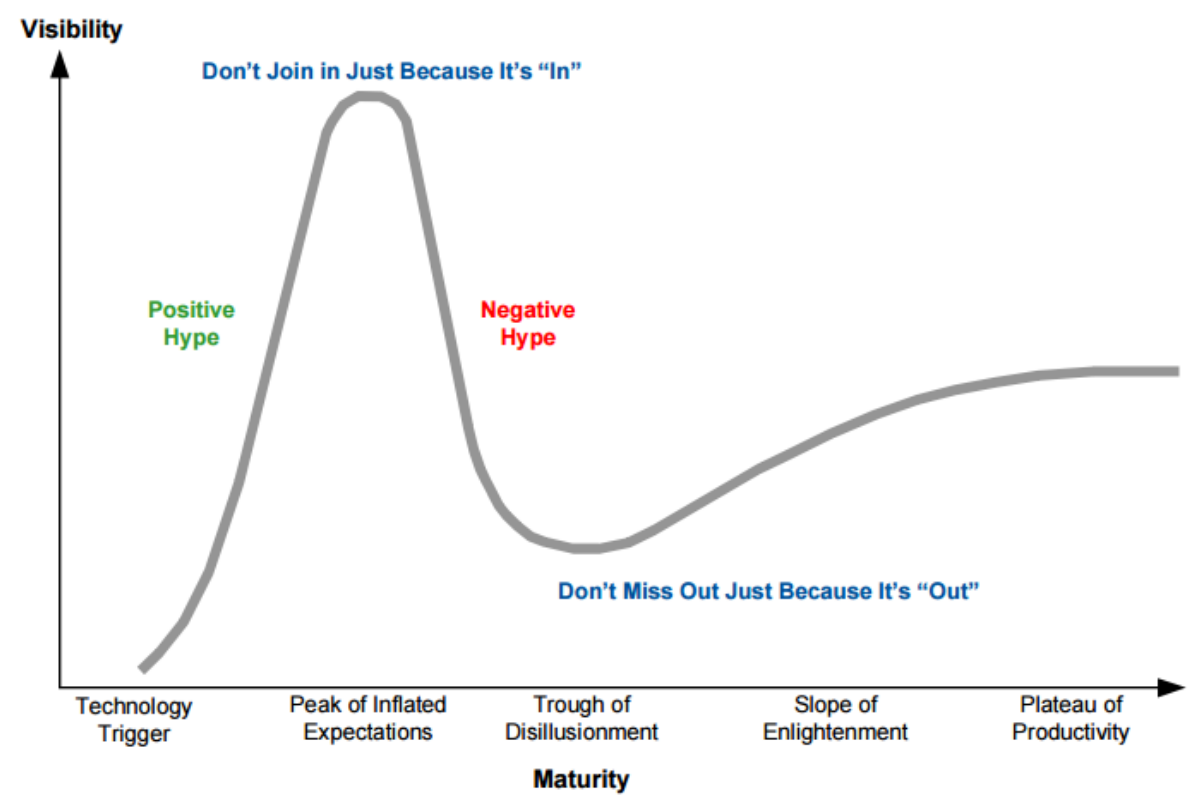

Fig. 1. The Gartner Hype Cycle Curve [13]

The five phases of the hype curve are described by Lajoie and Bridges [12].

\subsection{Gartner's Hype Cycles for Emerging Technologies: 2013 to 2016}

The 2013 and 2016 hype cycles are shown and elaborated on in this section to be able to look forward and backward regarding technology adoption in higher education institutions.

The 2013 Hype Cycle for Emerging Technologies

Figure 3 below describes the Hype Cycle for Emerging Technologies in 2013 [9]. 


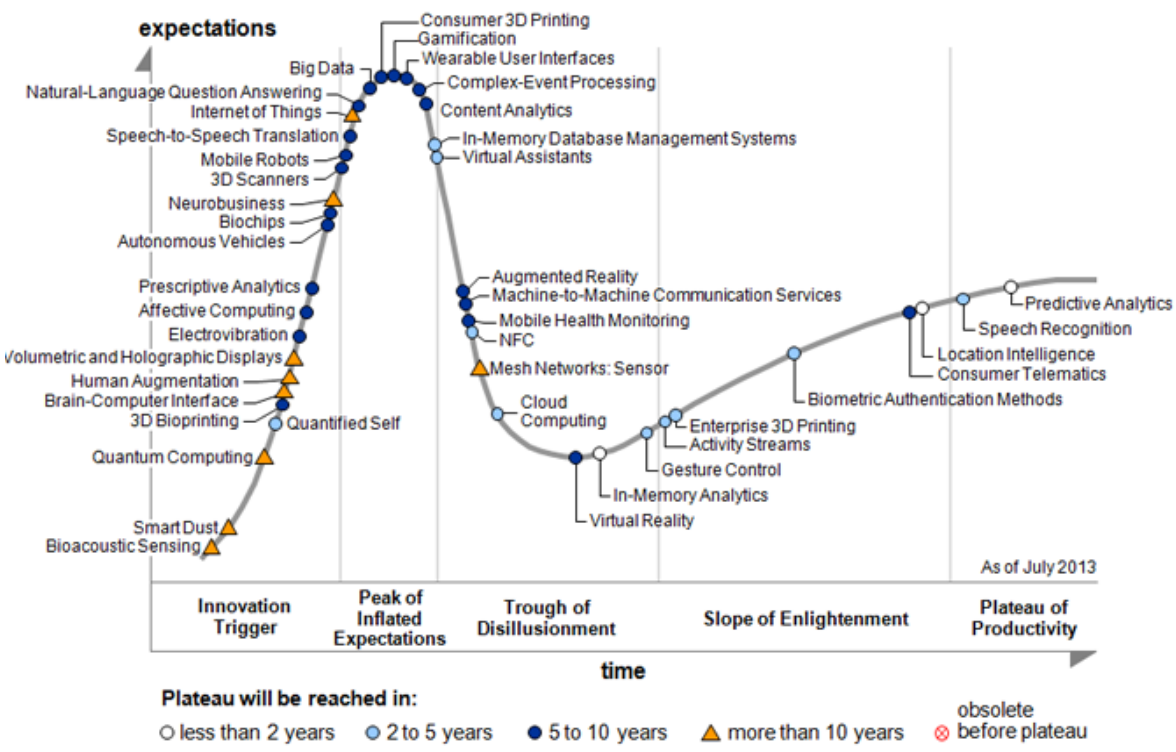

Fig. 2. Hy pe Cycle for Emerging Technologies, 2013 [9]

The 2016 Hype Cycle for Emerging Technologies

Figure 3 below describes the Hype Cycle for Emerging Technologies in 2016 [10].

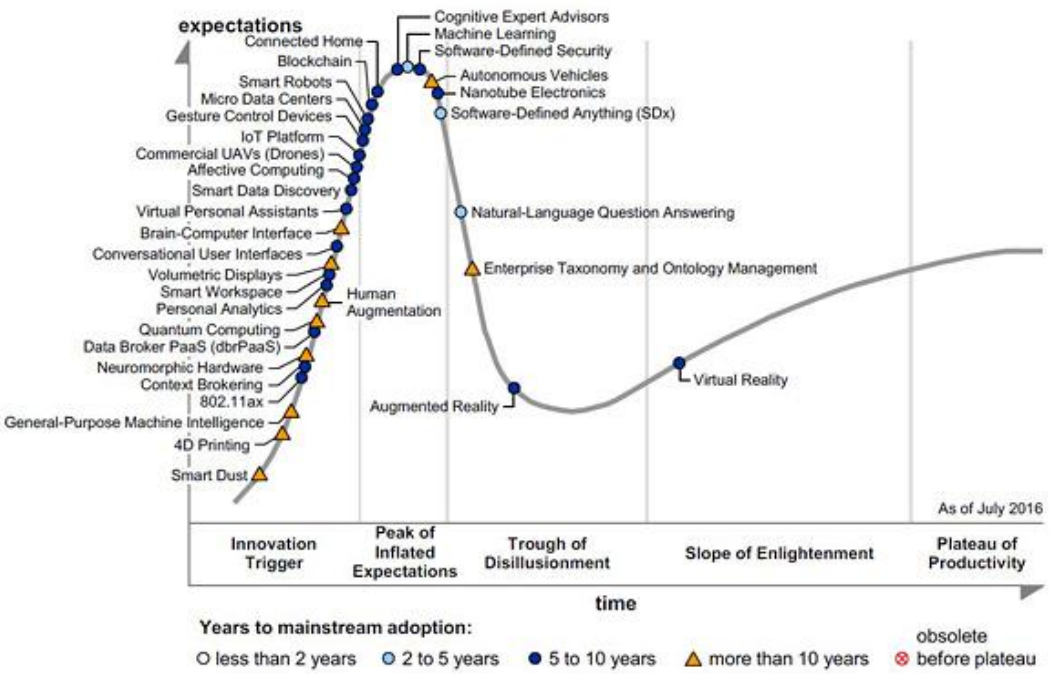

Fig. 3. Hy pe Cycle for Emerging Technologies, 2016 [10] 


\section{Research Question}

The main research question asked in this paper is: to what extend is higher education incorporating emerging technology trends compared to Gartner's Hype Cycle for Emerging Technologies?

The secondary questions are:

- How many trends identified in the 2013 Hype Cycle for Emerging Technologies have been adopted by higher education institutions from 2013 to 2016 ?

- How many trends identified in the 2016 Hype Cycle for Emerging Technologies have been adopted by higher education institutions from 2013 to 2016 ?

\section{$4 \quad$ Research Methodology}

The research methodology is a quantitative meta-analysis. Meta-analysis is used to synthesize quantitative information from related studies and produce results that summarize a whole body of research [6]. The selection criteria for the data gathering was:

\subsection{Identify the Study and Inclusions}

- To perform a specific Google Scholar search that included the words "tertiary institution" or "tertiary institutions" or "higher education" and the "keyword/s" identified in both the 2013 and 2016 Gartner Hype Cycles of Emerging Technologies [8, 10]. The dates were limited to 2013 to 2016 . The search criteria had to be very specific, only searching for the term "education", for example, would lead to incorrect results.

- To identify the same keywords from the Hype Cycles in the proceedings of the International Symposium on Emerging Technologies for Education (SETE) of 2016.

- To then give the total score of results from the two sets of data above in the Total column.

- To also perform a general Google Scholar search with only the keywords from the Hype Cycles from 2013 to 2016 to see if the trends identified have been researched at all in scholarly literature and to what extent.

\subsection{Exclusions}

The keywords had to be present in the results exactly as they are referred to by Gartner, limiting the possible number of search results. This was done because of timeand resource constraints. 


\subsection{Abstract the Data from the Study}

All the data was then summarized in two tables, Table 1 and 2.

\subsection{Analyze the Data Statistically}

A graph was plotted to identify the adoption of the trends by higher education institutions for the results of both the Hype Curves of 2013 and 2016.

\section{$5 \quad$ Results}

\subsection{Main Findings}

Gartner's Hype Cycle 2013

The keyword meta-analysis of the Gartner Hype Cycle for Emerging Technologies for 2013 is shown in Table 1 below.

Table 1. Keyword meta-analysis of the Gartner Hype Cycle for Emerging Technologies of $2013[8]$

\begin{tabular}{|c|c|c|c|c|c|c|c|}
\hline Ke yword from Hype Cycle & 2013 & 2014 & 2015 & 2016 & $\begin{array}{l}\text { SETE } \\
2016\end{array}$ & Total & $\begin{array}{c}\text { Total } \\
\text { General } \\
\text { Google } \\
\text { Scholar } \\
\text { Results }\end{array}$ \\
\hline \multicolumn{8}{|c|}{ On the Rise } \\
\hline Bioacoustic Sensing & 0 & 0 & 0 & 0 & 0 & 0 & 20 \\
\hline Smart Dust & 0 & 0 & 0 & 0 & 1 & 1 & 2820 \\
\hline Quantum Computing & 1 & 0 & 0 & 0 & 0 & 1 & 16300 \\
\hline 3D Bioprinting & 0 & 0 & 0 & 0 & 0 & 0 & 2200 \\
\hline Brain-computer Interface & 1 & 0 & 0 & 0 & 0 & 1 & 17100 \\
\hline Human Augmentation & 0 & 1 & 0 & 0 & 1 & 1 & 595 \\
\hline Volumetric and Holographic Display & 1 & 0 & 1 & 0 & 0 & 2 & 4 \\
\hline Electrovibration & 0 & 0 & 0 & 0 & 0 & 0 & 456 \\
\hline AffectiveComputing & 0 & 0 & 0 & 0 & 0 & 0 & 13400 \\
\hline Prescriptive Analytics & 0 & 0 & 0 & 0 & 0 & 0 & 1400 \\
\hline Autonomous Vehicles & 1 & 0 & 0 & 0 & 0 & 0 & 16500 \\
\hline Biochip & 0 & 0 & 0 & 0 & 0 & 0 & 15900 \\
\hline Neurobusiness & 0 & 0 & 0 & 0 & 0 & 0 & 61 \\
\hline \multicolumn{8}{|l|}{ At the Peak } \\
\hline 3D Scanners & 1 & 0 & 0 & 0 & 0 & 1 & 4100 \\
\hline Mobile Robots & 0 & 0 & 0 & 0 & 0 & 0 & 21000 \\
\hline Speech-to-Speech Translation & 0 & 0 & 0 & 0 & 0 & 0 & 1400 \\
\hline Internet of Things (IoT) & 2 & 0 & 0 & 1 & 0 & 3 & 46900 \\
\hline $\begin{array}{l}\text { Natural-Language Question Answer- } \\
\text { ing }\end{array}$ & 0 & 1 & 0 & 0 & 0 & 1 & 702 \\
\hline Big Data & 0 & 4 & 3 & 4 & 1 & 11 & 61400 \\
\hline Consumer 3D Printing & 0 & 0 & 0 & 0 & 0 & 0 & 216 \\
\hline Gamification & 0 & 3 & 2 & 3 & 1 & 6 & 16200 \\
\hline Wearable User Interfaces & 0 & 0 & 0 & 0 & 0 & 0 & 85 \\
\hline Complex-Event Processing & 0 & 0 & 0 & 0 & 0 & 0 & 6630 \\
\hline
\end{tabular}




\begin{tabular}{|c|c|c|c|c|c|c|c|}
\hline Keyword from Hype Cycle & 2013 & 2014 & 2015 & 2016 & $\begin{array}{l}\text { SETE } \\
2016\end{array}$ & Total & $\begin{array}{c}\text { Total } \\
\text { General } \\
\text { Google } \\
\text { Scholar } \\
\text { Results }\end{array}$ \\
\hline Content Analytics & 0 & 0 & 0 & 0 & 0 & 0 & 1040 \\
\hline \multicolumn{8}{|c|}{ Sliding Into the Trough } \\
\hline $\begin{array}{l}\text { In-Memory Database Management } \\
\text { Systems }\end{array}$ & 0 & 0 & 0 & 0 & 0 & 0 & 110 \\
\hline Virtual Assistants & 0 & 1 & 0 & 0 & 0 & 1 & 950 \\
\hline Augmented Reality & 0 & 1 & 2 & 3 & 1 & 7 & 27100 \\
\hline $\begin{array}{l}\text { Machine-to-Machine Communication } \\
\text { Services }\end{array}$ & 0 & 0 & 0 & 0 & 0 & 0 & 35 \\
\hline Mobile Health Monitoring & 0 & 0 & 0 & 0 & 0 & 0 & 1350 \\
\hline Near-Field Technology (NFC) & 0 & 0 & 1 & 1 & 0 & 2 & 318 \\
\hline Mesh Net works: Sensor & 0 & 0 & 0 & 0 & 0 & 0 & 55 \\
\hline Cloud Computing & 4 & 3 & 8 & 9 & 0 & 24 & 74400 \\
\hline Virtual Reality & 7 & 6 & 5 & 7 & 0 & 27 & 82500 \\
\hline In-Memory Analytics & 0 & 0 & 0 & 0 & 0 & 0 & 554 \\
\hline Gesture Control & 0 & 0 & 0 & 0 & 0 & 0 & 4850 \\
\hline \multicolumn{8}{|c|}{ Climbing the Slope } \\
\hline Active Streams & 0 & 0 & 0 & 0 & 0 & 0 & 556 \\
\hline Enterprise 3D Printing & 0 & 0 & 0 & 0 & 0 & 0 & 54 \\
\hline Biometric Authentication Methods & 0 & 0 & 0 & 0 & 0 & 0 & 447 \\
\hline Consumer Telematics & 0 & 0 & 0 & 0 & 0 & 0 & 96 \\
\hline Location Intelligence & 0 & 0 & 0 & 0 & 0 & 0 & 654 \\
\hline \multicolumn{8}{|c|}{ Entering the Plateau } \\
\hline Speech Recognition & 3 & 1 & 1 & 1 & 1 & 7 & 29400 \\
\hline Predictive Analytics & 0 & 1 & 0 & 0 & 0 & 1 & 16500 \\
\hline
\end{tabular}

It can be noted that "Cloud Computing" and "Virtual Reality" had the highest scores . Results for "Cloud Computing" at higher education institutions showed an upward trend, while the results for "Virtual Reality" remained mostly the same annually. The only other result worth mentioning was that of "Big Data", with a total score of 11 over the four study year period. Figure 4 below graphically illustrates how the hype curve trends have been adopted by higher education institutions, with the peak at the third phase and not the second, as with the typical Gartner Hype Curve. There was not enough data to do the analysis annually, so the results were totaled. 


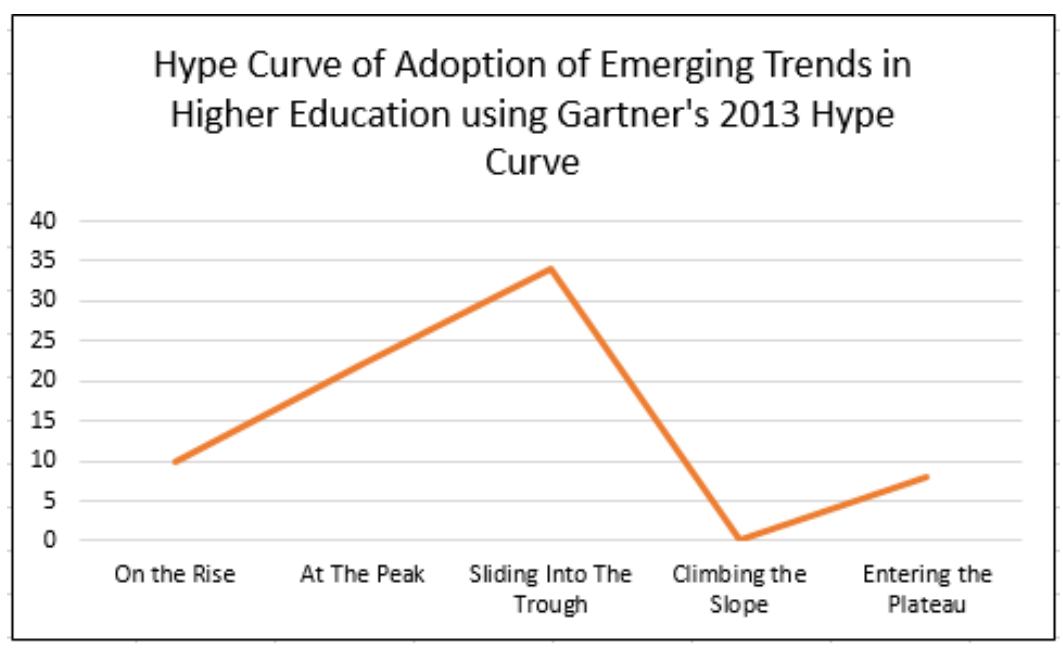

Fig. 4. The Hype Curve of Emerging Trends in Higher Education from 2013 to 2016 based on Gartner's Hype Cycle for Emerging Technologies of 2013

\section{Gartner's Hype Cycle 2016}

The keyword meta-analysis of the Gartner Hype Cycle for Emerging Technologies for 2016 is shown in Table 2 below.

Table 2. Keyword meta-analysis of the Gartner Hype Cycle for Emerging Technologies of $2016[10]$.

\begin{tabular}{|l|c|c|c|c|c|c|c|}
\hline \multicolumn{1}{|c|}{ Keyword from Hype Cycle } & $\mathbf{2 0 1 3}$ & $\mathbf{2 0 1 4}$ & $\mathbf{2 0 1 5}$ & $\mathbf{2 0 1 6}$ & $\begin{array}{c}\text { SETE } \\
\mathbf{2 0 1 6}\end{array}$ & Total & $\begin{array}{c}\text { Total } \\
\text { General } \\
\text { Google } \\
\text { Scholar } \\
\text { Results }\end{array}$ \\
\hline \multicolumn{7}{|c|}{ On the Rise - 2016 } \\
\hline Smart Dust & 0 & 0 & 0 & 0 & 1 & 1 & 2820 \\
\hline 4D Printing & 0 & 0 & 0 & 0 & 0 & 0 & 559 \\
\hline $\begin{array}{l}\text { General-Purpose Machine Intelli- } \\
\text { gence }\end{array}$ & 0 & 0 & 0 & 0 & 0 & 0 & 1 \\
\hline $\begin{array}{l}802.1 \text { lax - Next generation wireless } \\
\text { local area net works }\end{array}$ & 0 & 0 & 0 & 0 & 0 & 0 & 1680 \\
\hline Context Brokering & 0 & 0 & 0 & 0 & 0 & 0 & 29 \\
\hline Neuromorphic Hardware & 0 & 0 & 0 & 0 & 0 & 0 & 1120 \\
\hline Data Broker PaaS(dbrPaaS) & 0 & 0 & 0 & 0 & 0 & 0 & 1 \\
\hline Quantum Computing & 1 & 0 & 0 & 0 & 0 & 1 & 16300 \\
\hline Human Augmentation & 0 & 1 & 0 & 0 & 1 & 1 & 595 \\
\hline Personal Analytics & 0 & 0 & 0 & 0 & 0 & 0 & 478 \\
\hline Smart Workspace & 0 & 0 & 0 & 0 & 0 & 0 & 38 \\
\hline Volumetric Displays & 0 & 0 & 0 & 0 & 0 & 0 & 732 \\
\hline
\end{tabular}




\begin{tabular}{|c|c|c|c|c|c|c|c|}
\hline Keyword from Hype Cycle & 2013 & 2014 & 2015 & 2016 & $\begin{array}{l}\text { SETE } \\
2016\end{array}$ & Total & $\begin{array}{c}\text { Total } \\
\text { General } \\
\text { Google } \\
\text { Scholar } \\
\text { Results }\end{array}$ \\
\hline Conversational User Interfaces & 0 & 0 & 0 & 0 & 0 & 0 & 41 \\
\hline Brain-Computer Interface & 0 & 0 & 0 & 0 & 0 & 0 & 16800 \\
\hline Virtual Personal Assistants & 0 & 0 & 0 & 0 & 0 & 0 & 156 \\
\hline Smart Data Discovery & 0 & 0 & 0 & 0 & 0 & 0 & 20 \\
\hline Affective Computing & 0 & 0 & 0 & 0 & 0 & 0 & 13500 \\
\hline Commercial UAVs (Drones) & 0 & 0 & 0 & 0 & 0 & 0 & 19800 \\
\hline IoT Platform & 0 & 0 & 0 & 0 & 0 & 0 & 1940 \\
\hline \multicolumn{8}{|c|}{ At the Peak } \\
\hline Gesture ControlDevices & 0 & 0 & 0 & 0 & 0 & 0 & 34 \\
\hline Micro Data Centers & 0 & 0 & 0 & 0 & 0 & 0 & 151 \\
\hline Smart Robots & 0 & 0 & 0 & 0 & 0 & 0 & 426 \\
\hline Blockchain & 0 & 0 & 0 & 0 & 0 & 0 & 4700 \\
\hline Connected Home & 0 & 0 & 0 & 0 & 0 & 0 & 2260 \\
\hline Cognitive Expert Advisors & 0 & 0 & 0 & 0 & 0 & 0 & 2 \\
\hline Machine Learning & 0 & 0 & 0 & 0 & 1 & 1 & 262000 \\
\hline Soft ware-Defined Security & 0 & 0 & 0 & 0 & 0 & 0 & 131 \\
\hline Autonomous Vehicles & 0 & 0 & 0 & 0 & 0 & 0 & 16600 \\
\hline Nanotube Electronics & 0 & 0 & 0 & 0 & 0 & 0 & 1230 \\
\hline Software-Defined Anything (SDx) & 0 & 0 & 0 & 0 & 0 & 0 & 51 \\
\hline \multicolumn{8}{|c|}{ Sliding Into the Trough } \\
\hline $\begin{array}{l}\text { Natural Language Question answer- } \\
\text { ing }\end{array}$ & 0 & 0 & 0 & 0 & 0 & 0 & 702 \\
\hline $\begin{array}{l}\text { Enterprise Taxonomy and Ontology } \\
\text { Management }\end{array}$ & 0 & 0 & 0 & 0 & 0 & 0 & 1 \\
\hline Augmented Reality & 0 & 1 & 2 & 3 & 1 & 7 & 27100 \\
\hline \multicolumn{8}{|c|}{ Climbing the Slope } \\
\hline Virtual Reality & 7 & 6 & 5 & 7 & 0 & 27 & 82500 \\
\hline \multicolumn{8}{|c|}{ Entering the Plateau } \\
\hline None identified & & & & & & & \\
\hline
\end{tabular}

"Virtual Reality" was once again the top scorer, followed by "Augmented Reality". Only four of the other keywords scored once, namely "Smart Dust", "Quantum Computing", "Human Augmentation" and "Machine Learning". Figure 5 below show the how the hype curve trends have been adopted by higher education institutions based on Gartner's Hype Curve for Emerging Technologies for 2016. 


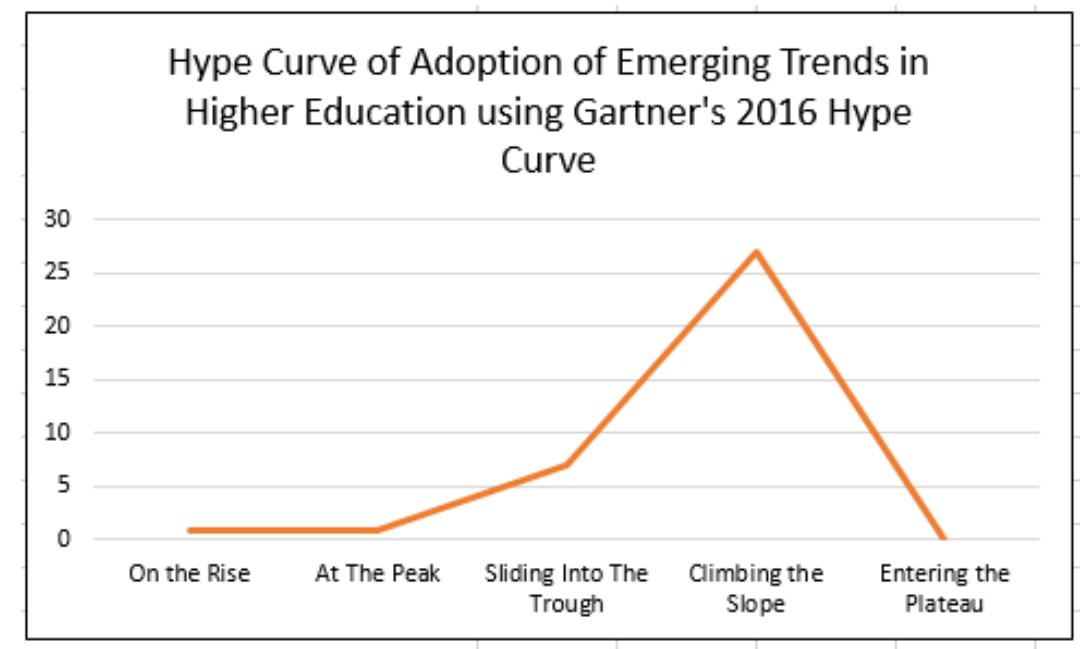

Fig. 5. The Hype Curve of Emerging Trends in Higher Education from 2013 to 2016 based on Gartner's Hype Cycle for Emerging Technologies of 2013

It can be seen from Figure 5 the graph looks almost the opposite of the Gartner Hype Curve, with the scores climbing in the third phase and peaking in the fourth phase. Again, the results were grouped and totaled for the four-year period.

\subsection{Discussion}

It is evident from Figure 4 and 5 that higher education institutions did not adopt the newest emerging technology trends. The 2013 Hype Curve begins to resemble the Gartner Hype Cycle for Emerging Technologies for 2013, but the peak is only at the third phase and not the second phase. "Virtual Reality" and "Cloud Computing" are most adopted in both the specific Google Scholar search as well as only the keywords themselves. The 2016 Hype Curve scores only on the third and fourth phases of the Gartner Hype Cycle for Emerging Technologies for 2016, with "Machine Learning" popular in the general keyword search, but only mentioned once in the specific keyword search. The results indicate that higher education institutions tend to adopt the technologies only once they reached maturity.

\section{Conclusion and Future Research}

It is concluded that only a handful of trends from both the 2013 and 2016 Gartner Hype Cycle for Emerging Technologies were adopted by higher education institutions. Possible reasons include budget constraints; taking a more conservative approach to new technologies; and adopting trends after they had proved to have wide acceptance. Bill Gates adapted the quotation of Roy Amara and said "we always overestimate the change that will occur in the next two years and underestimate the 
change that will occur in the next ten. Don't let yourself be lulled into inaction" [11]. As higher education institutions, it is our role and responsibility to expose students to new technologies, however, time and resources may be limited. We should not lose sight of the trends, but rather focus on innovative and less expensive ways of incorporating the trends into tertiary institutions. Future research could include to update the findings annually based on the new Hype Cycles published and also to include the context of the keywords, not only the exact keywords to obtain a broader picture.

\section{$7 \quad$ Acknowledgements}

The support given by the writing clinic presented by the Department of Research and Innovation at the University of Pretoria is gratefully acknowledged.

\section{References}

1. Aldunate R, Nussbaum M (2013) Teacher adoption of technology. Computers in Human Behavior, 29(3), 519-524

2. Altbach PG, Reisberg L, Rumbley LE (2009) Trends in global higher education: Tracking an academic revolution: UNESCO Pub.; Sense

3. Almara R (n.d.) Amara's Law. http://www.pcmag.com/ency clopedia/term/37701/amara-slaw

4. Borokhovski E, Bernard RM, Tamim RM, Schmid RF, Sokolovskay a A (2016) Technology-supported student interaction in post-secondary education: A meta-analy sis of designed versus contextual treatments. Computers \& Education, 96, 15-28

5. Dahlstrom E, Walker J, Dziuban C (2013) ECAR study of undergraduate students and information technology. Retrieved from https://library .educause.edu/ /media/files/library/2014/10/ers1406.pdf

6. Egger M, Smith GD (1997) Meta-Analy sis. Potentials and promise. BMJ: British Medical Journal, 315(7119), 1371

7. Fenn J, Raskino M (2008) Mastering the hy pe cycle: how to choose the right innovation at the right time: Harvard Business Press

8. Gartner Inc (2013a) Gartner's Hype Cycle Special Report for 2013. Retrieved from https://www.gartner.com/doc/2574916?ref=SiteSearch\&sthkw=Gartner\%27s\%20Hy pe\%2 0Cycle\%20Special\%20Report\%20for\%202013\&fnl=search\&srcId=1-3478922254

9. Gartner Inc (2013b) Gartner's 2013 Hype Cycle for Emerging Technologies maps out evolving relationship between humans and machines. Retrieved from http://www.gartner.com/newsroom/id/2575515

10. Gartner Inc (2016) Gartner's 2016 Hype Cycle for Emerging Technologies Identifies Three Key Trends That Organizations Must Track to Gain Competitive Advantage. Retrieved from http://www.gartner.com/newsroom/id/3412017

11. Gates, B (n.d.) Bill Gates Quotes BrainyQuote. Retrieved from https://www.brainy quote.com/quotes/quotes/b/billgates404193.html

12. Lajoie, EW, Bridges L (2014) Innovation decisions: Using the Gartner Hype Cycle. Library Leadership \& Management, 28(4)

13. Linden A, Fenn J (2003) Understanding Gartner's hype cycles. Strategic Analysis Report $N^{o}$ R-20-1971. Gartner, Inc 